\title{
Uma Leitura Pós-Keynesiana da Dinâmica de Preços e da Política Monetária no Brasil Pós- Metas de Inflação: uma Análise por Vetores Autorregressivos
}

\author{
Guilherme Jonas C. da Silva ${ }^{1}$ \\ Ana Paula Coutinho Viana ${ }^{2}$ \\ Fábio Henrique Bittes Terra ${ }^{3}$
}

\begin{abstract}
Resumo: O paper tem por objetivo analisar as raízes da inflação brasileira e a estratégia de condução da política monetária no Brasil via Regime de Metas de Inflação. Para tanto, realiza-se uma análise com Vetores Autorregressivos (VAR), utilizando dados da economia brasileira no período de 1999 a 2013. Os resultados demonstraram que a inflação no País é resultado de um conjunto de problemas, cujas causas não são exclusivamente provenientes do lado da demanda, o que torna o RMI pouco eficiente e muito custoso para combater a dinâmica da inflação verificada na economia brasileira. Assim, torna-se necessário repensar a estratégia de condução da inflação a meta estabelecida pelo Banco Central do Brasil, de modo a combater de forma mais eficaz as várias causas da inflação sem comprometer o potencial de crescimento da economia brasileira.
\end{abstract}

Palavras-chave: Meta de Inflação. Crescimento Econômico. Vetores Autorregressivos. Teoria PósKeynesiana. Brasil.

\section{Classificação JEL: E31, E52, E58.}

Abstract: The paper aims to analyze the roots of high inflation and the strategy of the Inflation Target Regime in Brazil`s monetary policy. In order to achieve this, we conduct an analysis with Vector Autorregressive Models(VAR), using data of Brazilian economy in the period from 1999 to 2013. The paper concludes that Brazilian inflation is the result of various problems, whose roots are not exclusively located on the demand side, which makes the Inflation Target Regime inefficient and very expensive in combating inflation observed in the Brazilian economy, considering that it does not control the supply side inflation. Thus, it becomes necessary to rethink the strategy driving the Inflation Target Regime used by Brazilian Central Bank, so to confront each of the causes of inflation without compromising the economic potential growth of the Brazilian economy.

Keywords: Inflation Target. Economic Growth. Vector Autoregressive. Post-Keynesian Approach. Brazil.

\section{Introdução}

O Regime de Metas de Inflação é, desde meados da década de 1990, o modelo de condução da política monetária utilizado explicitamente pelas Autoridades Monetárias de diversas economias do mundo, entre elas o Canadá (desde 1991), Reino Unido (1991), Suécia (1993), Austrália (1993), Chile (1999), Colômbia (1999), Brasil (1999), entre outras. Não obstante, há ainda a adoção não declarada do Regime de Metas para Inflação (doravante, RMI), como apontam Goodfriend (2004) para os Estados Unidos da América e Arestis\& Sawyer (2008) para o Banco Central Europeu. Em linhas gerais, o referido modelo tem seus fundamentos teóricos dados pelo chamado Novo

\footnotetext{
${ }^{1}$ Professor do Instituto de Economia da Universidade Federal de Uberlândia.

${ }^{2}$ Internacionalista pelo Curso de Relações Internacionais do Instituto de Economia da Universidade Federal de Uberlândia.

${ }^{3}$ Professor do Instituto de Economia da Universidade Federal de Uberlândia.
} 
Consenso Macroeconômico, cujo termo consenso refere-se às proposições convergentes de política macroeconômica feitas pelas escolas Novo-Clássica e Novo-Keynesiana.

Embora sejam escolas com distintas perspectivas sobre o comportamento do sistema econômico, elas comungam "um conjunto de princípios-chave - um núcleo de [hipóteses] macroeconômicas sobre as quais há amplo consenso" (TAYLOR, 1997, p. 233). A lógica operacional do RMI consiste em a política macroeconômica buscar um único objetivo geral, qual seja, a estabilidade inflacionária e, para tanto, utilizar-se imediatamente um de único instrumento, a taxa de juros da Autoridade Monetária. Assim, a política monetária, responsável pela execução do objetivo geral de estabilidade nos níveis de preço, é a mais importante política macroeconômica.

A teoria pós-keynesiana, que é uma perspectiva alheia ao Novo Consenso Macroeconômico e que se baseia nas contribuições sobre o funcionamento das economias monetárias da produção feitas por John Maynard Keynes, é crítica ao RMI. As principais críticas ressaltam o problema de a política macroeconômica deter um objetivo único e a própria natureza deste objetivo, ou seja, a estabilidade de preços, a incapacidade de a política monetária manter a estabilidade do sistema econômico por seus impactos sobre os investimentos produtivo e, até mesmo, a inabilidade do instrumento taxa de juros em reduzir a inflação, o que coloca em cheque toda a estruturação operacional do Regime (ARESTIS, 2006, 2009) (ARESTIS \& SAWYER, 1998, 2002, 2003a, 2003b, 2013) (ARESTIS et ali, 2009) (CARVALHO, 2005).

Neste contexto, o objetivo deste artigo é estudar as causas da dinâmica da inflação no Brasil de 1999 a 2013, relacionando-as com a eficiência da política monetária sob o RMI em promover a estabilidade do nível de preços e o crescimento do emprego e do produto.Para tanto, foram efetuados testes com Vetores Autorregressivos, buscando-se compreender quais elementos causais mais impactaram em variações positivas nos preços. De antemão, pode-se afirmar que os testes mostram que o comportamento da inflação é resultado de um mix de problemas e não decorre de choques de demanda. Assim, o RMI é pouco eficiente, e muito custoso, para combater a inflação verificada no País, pois não trata diretamente dos problemas que respondem por grande parte da trajetória dos preços no período em análise.

Para alcançar seus objetivos, este artigo está estruturado da seguinte forma, na segunda seção serão descritos os aspectos da lógica teórica e operacional do RMI, tal qual exposto pelo Novo Consenso Macroeconômico. Na terceira seção, são apresentados os aspectos da crítica póskeynesiana ao RMI, com ênfase no caso brasileiro. Ademais, esta seção se apoiará, para corroborar as críticas de inspiração pós-keynesiana, na apresentação e na análise de estatísticas descritivas de variáveis relevantes. Na quarta seção, apresenta-se o modelo das regressões com Vetores Autorregressivos, além da base de dados e, após isso, são feitos os exercícios econométricos por 
meio dos quais se buscará entender o que condicionou a dinâmica da inflação no Brasil pós-RMI. Apresentados os resultados, realiza-se, ainda nesta seção, o debate deles e breves proposições de políticas econômicas. Por fim, são tecidas as considerações finais.

\section{O Novo Consenso Macroeconômico e o Regime de Metas de Inflação}

Até início dos anos 1990, a formulação da política monetária concentrou-se na determinação da taxa de crescimento da oferta de moeda em relação à meta estipulada para alcançar a taxa de juros de equilíbrio, sob clara inspiração monetarista à lá Friedman. Desde então, os Bancos Centrais adotam o RMI.Neste regime, o componente foward looking das expectativas dos agentes otimizadores (sejam produtores maximizadores de lucros, sejam consumidores maximizadores de utilidade) faz com que as funções a serem maximizadas sejam intertemporais. Logo, a otimização passa a ser dinâmica, implicando jogos repetitivos sem fim definido entre Autoridade Monetária (AM) e os agentes (BARRO\&GORDON, 1983).

Segundo Mankiw (2012), essa abordagem pode ser representada por modelo dinâmico simples para a demanda e a oferta agregadas, já que este concentra sua atenção no modo como as variáveis endógenas, quais sejam, o produto e a inflação, reagem ao longo do tempo, às modificações exógenas no ambiente econômico. Por sua vez, o nível natural de produção, a meta de inflação, o choque de demanda, o choque de oferta, e a taxa de inflação defasada são as variáveis exógenas ou pré-determinadas do modelo. Algebricamente, tem-se:

$Y_{t}=\bar{Y}_{t}-\alpha\left[\pi_{t}-\pi_{t}^{*}\right]+\beta \varepsilon_{t}$

Demanda Agregada Dinâmica

$\pi_{t}=\pi_{t-1}+\phi\left[Y_{t}-\bar{Y}_{t}\right]+v_{t}$

Oferta Agregada Dinâmica

em que: $Y_{t}=$ produção total de bens e serviços; $\bar{Y}_{t}=$ nível natural de produção; $\varepsilon_{t}=$ choque exógeno de demanda; $\pi_{t}=$ taxa de inflação; $\pi_{t}^{*}=$ meta de inflação; e $v_{t}=$ choque exógeno de oferta.

Por conta das expectativas racionais, os ajustes dos mercados podem ser lentos, porque dependem da interação entre a AM e os agentes. Os policy makers imbuídos do viés inflacionário têm a tendência de instituir políticas econômicas expansionistas, emitindo moeda e ampliando o emprego além de seu nível natural, o que pressiona tanto a demanda agregada quanto o nível nominal de salários. $\mathrm{O}$ aumento dos salários eleva os custos marginais dos produtores que, para evitarem perdas intertemporais em seus markups, elevam seus preços. Portanto, a expansão monetária causa a ampliação da demanda agregada, do emprego e da produção correntes, porém com aumentos nos preços. Assim, efetiva-se o trade-off de curto prazo entre emprego e inflação previsto pela Curva de Phillips.

O viés inflacionário provoca, por sua vez, uma inconsistência dinâmica na alocação de recursos dos agentes. Suas expectativas foward looking, contudo, fazem com que eles retaliem a 
AM, porquanto percebam o oportunismo dela. De acordo com Bernanke \& Miskhin (1997, p. 14) este jogo não cooperativo,

leva a AM a tentar enganar o público com surpresa inflacionária, induzindo produtores $[\ldots]$ a crescer o produto e o emprego acima do nível natural. Se o público possui expectativas racionais, entretanto, ele antecipará as ações do Banco Central e os produtores não serão enganados.

As expectativas foward looking em um cenário de interação repetitiva torna os parâmetros das funções objetivo dos agentes bastante sensíveis às políticas econômicas. Na ausência de credibilidade, em função de inconsistência dinâmica passada, os agentes mantêm suas expectativas de inflação no futuro, mesmo diante do anúncio de políticas contracionistas para desinflação (e de esforços para tanto) da AM. Em oposição, com transparência, consistência entre anúncio e resultado, boa reputação e, logo, credibilidade, a AM conseguirá fazer com que sua interação com os agentes implique-lhes crenças de que uma política de estabilidade será perene. Por esperarem menor inflação futura, os agentes remarcam seus preços, diminuindo-os gradualmente até que os desvios das expectativas se extingam e o sistema econômico siga sua trajetória de equilíbrio de longo prazo.

Caso contrário, ou seja, se a AM no curto prazo persistir em utilizar-se do viés inflacionário, os resultados alcançados no longo prazo serão, segundo Bernanke \& Mishkin (1997, p. 14) “uma inflação mais elevada do que o ótimo, sem benefícios em termos de menor desemprego". Em outras palavras, a economia se encontrará em um ponto subótimo, consoante Kydland \& Prescott (1977), com maior patamar de preços no longo termo, sem qualquer desvio do emprego e do produto em relação a seus níveis de equilíbrio. A propósito, para que ocorram modificações no produto real de longo prazo, são necessários progressos técnicos nas funções de produção, ou seja, incrementos na capacidade de oferta da economia. Apenas isto fará, e não políticas econômicas expansionistas, com que as novas combinações de fatores provoquem ganhos de produtividade e elevem o produto.

Deste arcabouço surge a necessidade de que o viés inflacionário seja contido, para a economia trilhar seu percurso sem distorções nas alocações de recursos. Em âmbito geral, a causa da inflação é a demanda agregada ampliada pelo aumento do emprego além de seu nível natural. Esse processo resulta das políticas de easy money da AM e, assim sendo, deve existir uma regra que constranja quaisquer possíveis ações discricionárias dos policy makers, tornando a conduta da política monetária consistente, crível e indutora da cooperação dos agentes, por "manter o crescimento da demanda agregada estável objetivando prevenir flutuações no produto real e na inflação" (TAYLOR, 1997, p. 234).

Neste cenário, a meta de inflação tornou-se a regra, ou seja, o constrangimento que demonstra todos os esforços que a AM faz para manter a inflação sob controle. Para tanto, a política 
monetária deve ser ativa e "gerenciar a demanda agregada" (GOODFRIEND \& KING, 1997, p. 26) e o instrumento utilizado, por excelência, é a taxa de juros nominal básica. Dada pela Regra de Taylor, a função de reação da AM pode ser representada como segue:

$i_{t}=\pi_{t}+r_{t}+\phi_{\pi}\left[\pi_{t}-\pi_{t}^{*}\right]+\phi_{Y}\left[Y_{t}-\bar{Y}_{t}\right]$

Regra Para a Política Monetária

em que: $i_{t}$ é a taxa de juros básica (ou nominal); $r_{t}$ é a taxa natural de juros reais; e $\phi_{\pi}, \phi_{y}=$ parâmetros positivos da política econômica, que mostram como a AM reage às oscilações na inflação e no produto, respectivamente. A regra baseia-se nos juros, pois eles são um instrumento de simples compreensão pelos agentes e oferecem à política monetária flexibilidade e eficiência para o gerenciamento da demanda agregada (TAYLOR, 1993).

Nesse particular, os juros afetam a atividade econômica por meio das expectativas que orientam as funções objetivo a serem maximizadas pelos agentes vis-à-vis os preços relativos da cesta de bens e serviços que eles acessam. Ao definir a taxa de juros básica, mudam-se os custos relativos presentes e futuros. Aumentos nos juros sugerem maior benefício da poupança no presente e, ao provocarem a substituição intertemporal nas alocações dos agentes, implicam menor demanda agregada. Reduções nos juros provocam reações no sentido contrário. Por sua vez, quando a inflação é causada por choques de oferta, a política monetária pode acomodá-la sem necessariamente alterar os juros, seja pelo uso de bandas de inflação, ao invés da meta, seja pelo espaço de tempo de convergência da inflação ao alvo.

Arestis et al (2009) apresentam ainda outros aspectos operacionais que cumprem papel auxiliar à taxa de juros na condução da política monetária. Dentre os elementos utilizados destaquem-se os relatórios de inflação, a clareza nas informações publicadas, as reações rápidas a choques de demanda, a abrangência e o realismo dos modelos de previsão de inflação, a independência da AM ou, quando esta não for possível, sua autonomia operacional. Os referidos aspectos buscam conferir transparência à atuação da AM e baseiam a busca que ela faz pela credibilidade.

Para manter os juros no patamar estabelecido, a AM atua no mercado monetário, comprando e vendendo títulos públicos aos bancos comerciais. Ao definir, pela Regra de Taylor, um determinado patamar de juros nominais, a AM passa a controlar a liquidez no mercado monetário, a bem de que isso se espalhe pelos outros mercados do sistema financeiro, principalmente o de crédito e o de capitais, responsáveis pelo financiamento do consumo das famílias e dos investimentos das empresas.

Ao modificar a taxa de juros, a AM acaba por alterar o custo de oportunidade relativo dos ativos em geral, desde os mais líquidos - isto é, os meios de pagamento - até os mais ilíquidos, 
quais sejam, os investimentos em bens de capital. Com isto, tanto a atratividade dos investimentos em bens de capital se tornará menor relativamente aos ativos financeiros quanto os empréstimos tomados para financiar o consumo e o investimento se tornarão mais caros e englobarão uma maior parcela da restrição orçamentária dos agentes. Logo, a demanda presente torna-se desestimulada, levando à desinflação.

Caso se esteja em uma economia aberta com livre mobilidade de capitais e de produtos, a elevação das taxas de juros, ao implicar uma estrutura a termo da taxa de juros mais atrativa no mercado financeiro doméstico vis-à-vis o internacional, provoca um influxo de capitais no mercado cambial, apreciando a taxa de câmbio. Com isso, somam-se outros dois esforços ao controle dos preços. Por um lado, a oferta doméstica passa a ser complementada de forma menos custosa pela produção internacional ao passo em que a demanda externa se arrefece. Por outro lado, há um choque positivo de oferta, em função da redução dos custos de produção via efeito pass-through. Ressalte-se que, se o influxo de capital pela conta financeira for superior à saída de recursos pela conta comercial, o excesso de liquidez que o setor externo implicar sobre a base monetária reduzirá as curvas de juros do sistema financeiro, reduzindo a atratividade dos ativos domésticos em relação aos do resto do mundo. Sob os princípios do NCM, a taxa de câmbio de equilíbrio será encontrada tão logo os fluxos de capital no mercado cambial se ajustem às condições de curto prazo.

Por fim, se o governo não exercer o viés inflacionário, o crescimento do estoque de moeda ocorrerá pari-passu ao crescimento do produto, na medida necessária para viabilizar que a demanda absorva a oferta de bens e serviços. Prevalecem as condições que tornam os mercados eficientes, em que a oferta e a demanda estipulam o nível de preços que sinaliza aos agentes a alocação ótima dos recursos em pleno emprego e dentro dos limites estabelecidos pelo produto potencial.

Em suma, foram apresentadas, ainda que forma resumida, as estruturas teórica e operacional do RMI. Tal proposição de política monetária é a realidade em uma série de países desde início dos anos 1990. Como se sabe, o Brasil o adotou oficialmente em julho de 1999, uma vez que em janeiro do mesmo ano o regime de âncora cambial, vigente a partir de 1994, foi abandonado com a eclosão da crise brasileira em fins de 1998. A seguir, passa-se à uma apreciação pós-keynesiana, portanto crítica, aos anos de RMI no País.

\section{Aspectos da crítica pós-keynesiana ao Regime de Metas de Inflação no Brasil}

Como se sabe, o regime de metas de inflação foi implementado no Brasil em 1999 em um contexto de desequilíbrio externo e crise fiscal,resultantes das políticas econômicas do Plano Real. A entrada de capital estrangeiro era o principal fator que permitia ao País manter a âncora cambial. O ataque especulativo que ocorreu em 1999 teve um duplo efeito, por um lado, tornou evidentes os limites de uma política de valorização do câmbio num contexto de abertura econômica e 
instabilidade do sistema financeiro internacional e, por outro lado, retirou do Banco Central do Brasil (BCB) a possibilidade de manutenção da política de controle da inflação por intermédio do ancoragem à taxa de câmbio (OREIRO\& CURADO, 2005).O BCB foi forçado a flexibilizar o regime cambial para responder às fortes pressões sobre as reservas internacionais em janeiro de 1999 e em julho do mesmo ano o RMI tornou-se a regra de condução da política monetária (ARESTIS et ali, 2009).

No RMI, inverteram-se os papéis dos instrumentos em relação ao que prevalecia na âncora cambial: a taxa de câmbio, flexível, tornou-se a principal variável de ajuste do balanço de pagamentos, porquanto a taxa de juros tornou-se o instrumento central de controle dos preços (MODENESI, 2005). A taxa de juro no RMI passou a ser menor do que a em vigor durante regime monetário anterior, em decorrência de a taxa de câmbio responder às oscilações no setor externo. Entretanto, os juros continuaram positivamente diferenciados em relação aos juros médios internacionais. Por um lado, a necessidade de contenção de demanda agregada interna para o alcance das metas de inflação contribuiu para a manutenção de elevadas taxas de juros. Por outro, ampliaram-se os riscos de contaminação dos preços domésticos pelas desvalorizações cambiais verificadas em função do novo modelo de flutuação cambial adotado (CARVALHO \& FERRARI FILHO, 2004).

Mesmo com a vigência de juros substanciais, a associação câmbio flutuante e livre mobilidade de capitais - relacionados ainda à característica de país emergente do Brasil - fez com que as taxas de câmbio, nominal e real, apresentassem uma elevada volatilidade com significativas desvalorizações, principalmente entre 2001 e 2003, como mostra o Gráfico 1, abaixo. Consequentemente, a inflação sofria impactos via pass-through câmbio-custos-preços. Embora os riscos de contaminação dos preços domésticos reduziram-se com a valorização cambial após 2004, a AM continuamente alegava que pressões de demanda agregada justificavam a manutenção dos patamares elevados dos juros da economia brasileira. Nas palavras de Arestis et al,

durante o regime de IT [Inflation Targeting], a taxa de juros tem sido muito alta. Entre 1999 e 2005, a taxa média de juros, Selic, foi da ordem de 19,6\%, enquanto a taxa de juros real [...] apresentou média anual de 10,5\%. Esta tem sido elevada devido à rigidez da política monetária, que é focada na manutenção, a qualquer custo, do controle da inflação (2009, p. 17).

Os Gráficos 1 e 2, a seguir, mostram o comportamento do câmbio, da taxa de juros básica nominal e da inflação após a implementação do RMI, em 1999. Como se pode ver, os choques inflacionários ocorrem entre 2001 e 2003, em função do chamado 'Efeito-Lula', em que os capitais internacionais temerários sobre o destino da economia brasileira face à então iminente vitória eleitoral do candidato de esquerda, Lula da Silva, não renovaram sua dívidas vincendas e produziram um refluxo de capitais do País (CARVALHO \& FERRARI FILHO, 2004). O Gráfico 2, 
por sua vez, mostra que, como reação ao elevado impacto inflacionário, este foi o período de maior taxa Selic desde o fim da âncora cambial em 1999. Após este choque cambial e a consequente resposta dada a ele pela taxa de juros, o câmbio apenas passou a sofrer novo impacto em fins de 2008, com a eclosão da crise econômica internacional. Contudo, dado a recessão econômica produzida pela referida crise, as pressões inflacionarias e sobre os juros básicos não voltaram a se verificar. Porém, em linhas gerais, pode-se apontar as seguintes linhas gerais: os juros tenderam à queda, porém, partindo de um nível bastante elevado, de aproximadamente $40 \%$ ao ano (a.a.) em 1999 para o entorno de $10 \%$ em 2013. A taxa de câmbio, como resposta à este elevado nível de juros e também aos superávits correntes obtidos entre 2004 e 2007 (IPEADATA, 2013), deteve forte tendência de apreciação. Por fim, observa-se na inflação - medida pelo Índice de Preços ao Consumidor Amplo (IPCA) - respondendo à valorização cambial e ao patamar dos juros, uma muito suave tendência de declínio. Caso se considere apenas o período pós-choque cambial de 2001-2003, a inflação situa-se em torno de sua tendência.

Gráfico 1 - Taxa de Câmbio Nominal (R\$/US\$) e Índice de Preços ao Consumidor - Amplo (IPCA) (\%), 1991/1 a 2013/1, trimestral

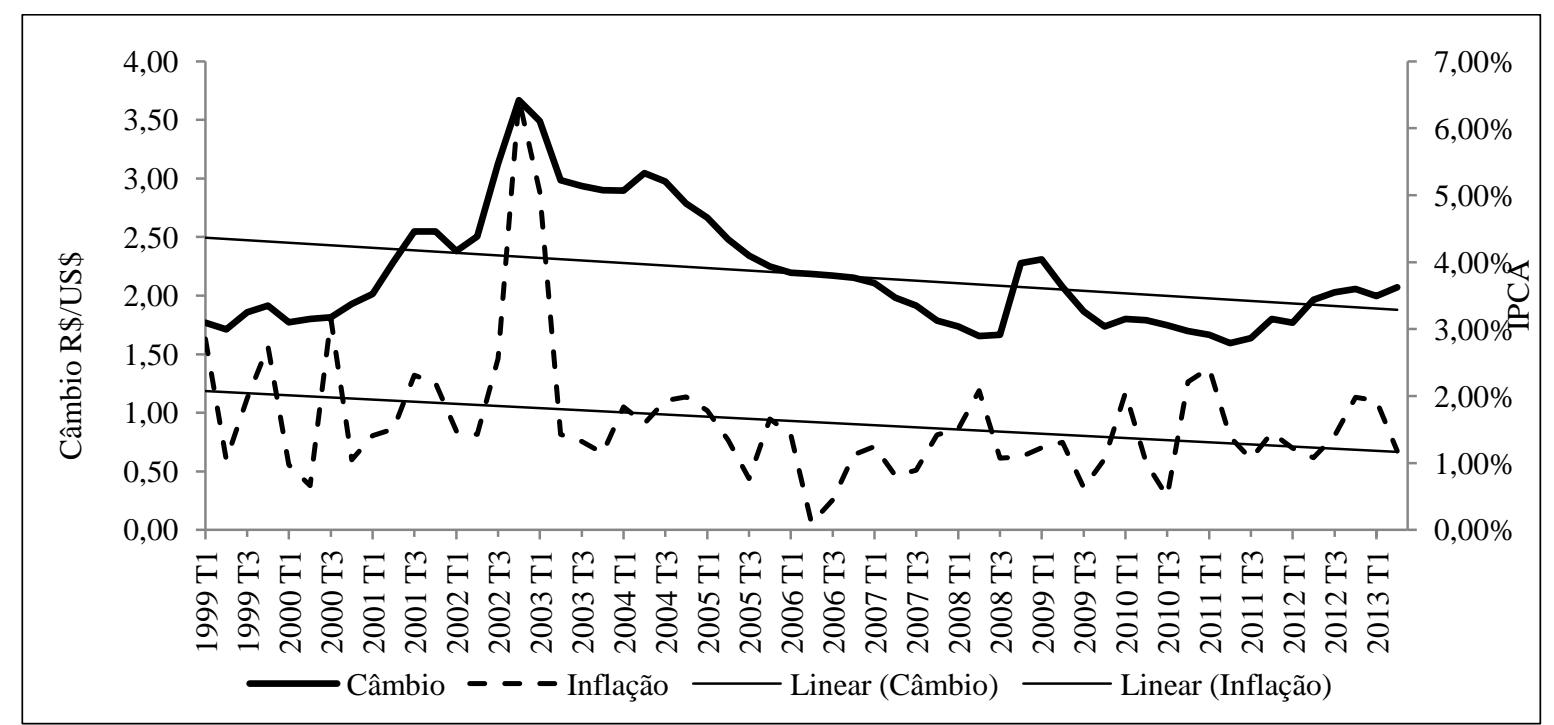

Fonte: Elaboração própria a partir de dados IPEADATA (2013) e BCB (2013) 
Gráfico 2 - Taxas de Juros Básica Nominal (Selic ao ano) e IPCA 1999 a 2013, (\% ao trimestre)

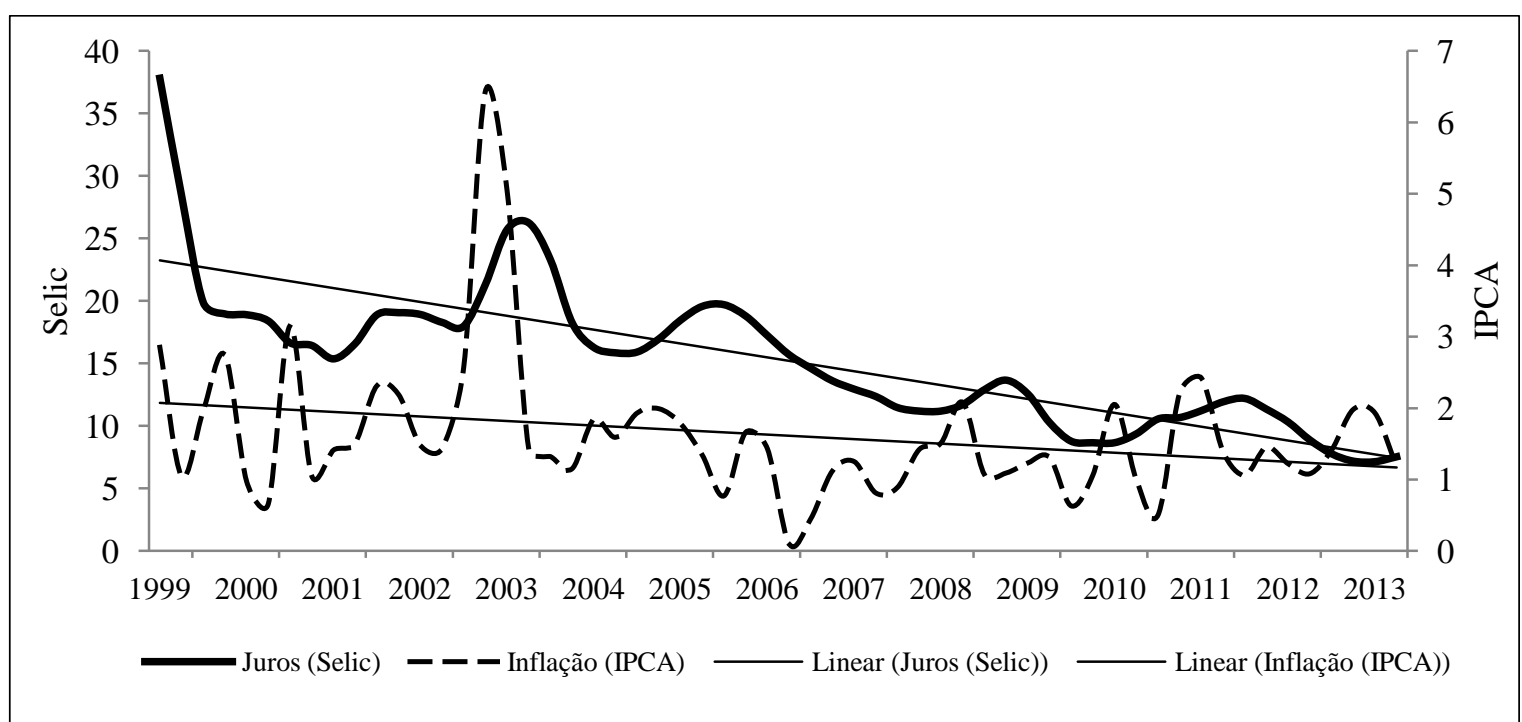

Fonte: Elaboração própria a partir de dados IPEADATA (2013) e BCB (2013)

Nestas condições de imobilidade da taxa de juros rumo a níveis concernentes às estabelecidas no mercado mundial, Carvalho \& Ferrari Filho argumentam que,

no Brasil, o incremento das taxas de juros tem alguns efeitos perversos. A maioria da riqueza financeira detida pelo setor privado está na forma de dívida pública [...] as altas taxas de juros fazem com que os gastos fiscais se elevem, aprofundando qualquer desequilíbrio fiscal que se tenha de partida (2004, p. 60).

Portanto, um dos efeitos imediatos das elevadas taxas de juros foi sobre o comportamento das finanças públicas. Nesse particular, Arestis et al (2009) denotam a trilha pela qual a taxa de juros impacta sobre o endividamento público,

o Brasil é o único país do mundo onde o Banco Central determina diretamente as taxas de juros que remuneram a dívida pública e essas são usadas também como meta operacional de política monetária [...] logo, qualquer aumento nas taxas de juros resulta em um aumento imediato do estoque total da dívida pública (2009, p. 22). 
Gráfico 3 - Pagamentos de Juros Nominais, Superávit Primário do Governo Federal com Banco Central do Brasil e Dívida Mobiliária Federal ${ }^{4}, 1999$ a 2003 (mensal em R \$ milhões)

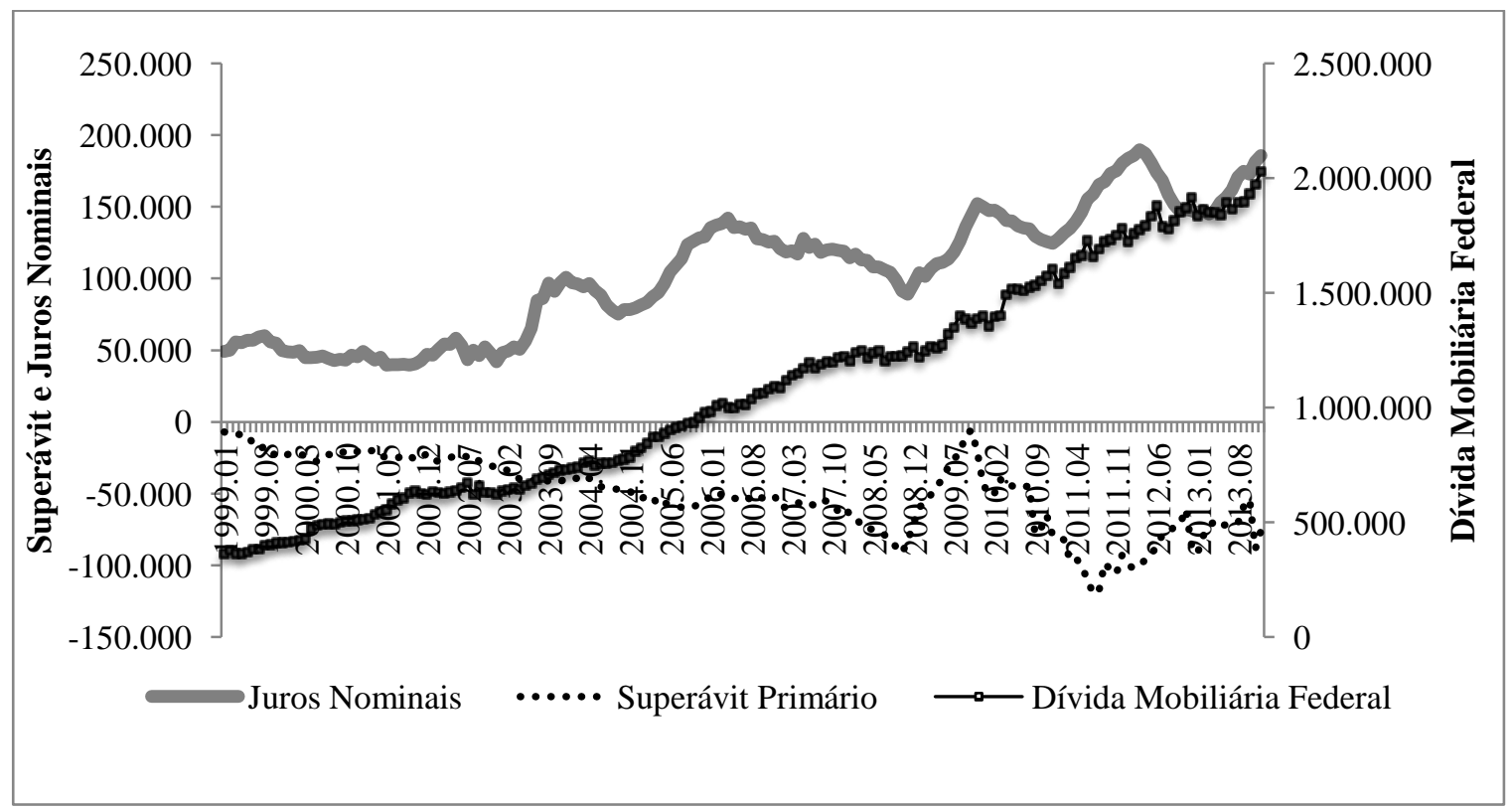

Fonte: Elaboração própria a partir de dados IPEADATA (2013)

Notas: (-) = positivo, pois, o critério é o de déficit público.

O Gráfico 3, acima, reflete justamente o peso fiscal dos elevados juros nominais mantidos pela AM para conduzir a política monetária. Muito embora se tenham superávits primários em todo o período, eles foram insuficientes para fazer frente ao elevado pagamento de juros que, mesmo defronte uma taxas de juros em queda, ampliou-se em todo o período. Este maior desembolso com juros relaciona-se à ampliação do endividamento mobiliário federal entre 1999 e 2013, em uma relação endógena:os juros da política monetária causam o déficit fiscal (mesmo contando com uma poupança de recursos primários que buscam o equilíbrio orçamentário) e à medida que o estoque de dívida pública assim se expande, o pagamento de juros aumenta, mesmo que a taxa Selic se reduza. A ausência de elementos auxiliares aos juros na condução da política monetária acaba por retroalimentar a endogenia dívida maior/maior pagamento de juros apresentada no Gráfico 3 e a penalizar a política fiscal com custos financeiros elevados de curto e de longo prazos, pois os títulos públicos destinados à cobertura dos déficits nominais (de longo prazo) incorporam os juros de curto prazo da política monetária, caso contrário, o custo de oportunidade não levaria à demanda voluntária por dívida pública de curto prazo. A repercussão dos juros da política monetária, desta forma, ocorre de forma intertemporal sobre os gastos financeiros federais.

\footnotetext{
${ }^{4}$ Dívida mobiliária federal é o melhor indicador do peso fiscal da política monetária, pois é ela que representa o estoque de títulos públicos utilizados nas operações de mercado aberto da AM, meio pelo qual se alcança a meta estipulada de juros. Ademais, a política monetária é responsabilidade exclusiva do Governo Federal de forma que se utilizar a variável dívida líquida do setor público envolveria mais esferas do setor público do que a Federal, distorcendo a análise.
} 
Ademais, uma das principais críticas que autores pós-keynesianos lançam sobre o RMI é o de ele lidar com a inflação como se ela fosse um fenômeno cuja causa sejam impactos de demanda, principalmente decorrentes de políticas de easy money da AM - algo que o Gráfico 3 contesta, pois, em termos de política fiscal propriamente dita, há superávit primário em todo o período.De maneira diversa, a teoria pós-keynesiana "enxerga a inflação como sendo causada por múltiplos fatores, cujas causas variam ao longo do tempo" (ARESTIS \& SAWYER, 2013 p.2). Então, a política monetária para os pós-keynesianos demanda um conjunto maior de instrumentos e de políticas, além da taxa de juros, para alcançar a estabilidade de preços.

Embora o RMI aceite que choques de oferta podem ocorrer e preveja mecanismos para amortecê-los, como as bandas em relação tanto ao alvo da inflação quanto ao tempo de alcance dela, a reação da AM dá-se com a política de juros, que tem efeitos demorados e indiretos sobre as diversas outras causas da inflação, como a valorização dos salários, os preços administrados, os preços das commodities, o conflito distributivo e as expectativas dos agentes marcadores de preços. Excetuem-se, apenas, os efeitos dos juros sobre a taxa de câmbio que, a depender do expectativa especulativa dos agentes e do grau de abertura financeira da economia, podem ser rápidos. Nesse particular, Araújo \&Modenesi (2012) mostram, por meio de uma análise de decomposição da variância do IPCA, que o câmbio respondeu por $8 \%$ da explicação do comportamento do referido Índice após a implementação do RMI. Pressões de oferta e de demanda responderam por 2,4\% e $2,5 \%$, respectivamente. Ainda que os juros possam atuar com rapidez sobre o câmbio que, como visto, explica muito do comportamento do IPCA, ele tem poucos efeitos sobre, por exemplo, os preços administrados que, por sua vez, exercem influência sobre a inflação, como mostra o Gráfico 4, a seguir.

Gráfico 4 - Dinâmica da inflação: preços administrados e IPCA, 1999 a 2012 (anual, em \%)

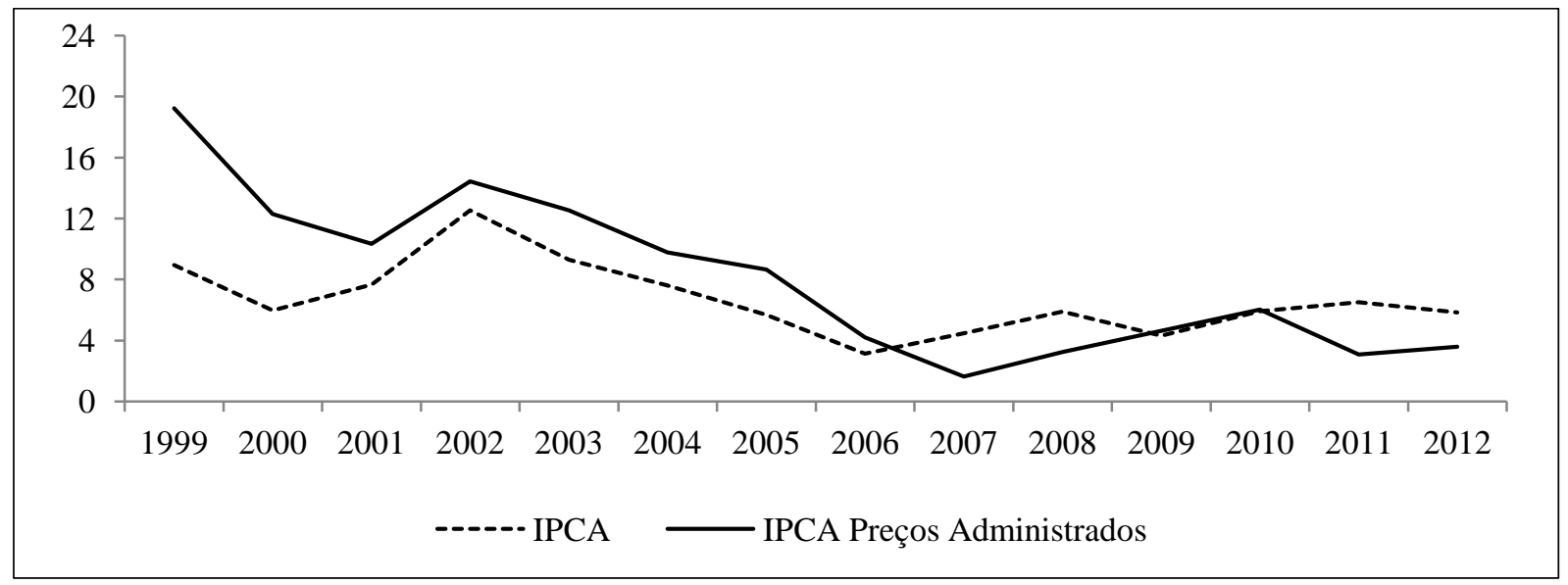

Fonte: Elaboração própria a partir de dados BCB (2013) 
A lógica da administração de preços e da indexação implica o comportamento expresso no Gráfico 4 entre preços administrados e índice cheio: ambas variáveis caminham com bastante correlação e vão mutuamente se causando ao longo do tempo. O problema é que os juros exercem pouca influência sobre o comportamento dos preços administrados ${ }^{5}$. O principal caminho, a se basear em Arestis et al (2009), é o efeito dos juros sobre o câmbio e destes para os custos operacionais das empresas sob administração de preços. Outro caminho esperado, são os juros arrefecerem a atividade econômica a ponto de implicarem taxas de inflação que tendam a zero, eliminando-se, assim, a necessidade de reajuste de preços, algo que, em nível, prático, e com base na própria história contada pelo IPCA nos Gráficos 1, 2 e 4, não acontece.

Como se não bastasse, há ainda o problema do canal de transmissão dos juros para a demanda agregada ser pouco eficiente no Brasil, em função da maciça presença de títulos pósfixados no estoque de riqueza dos agentes. Assim, o efeito riqueza dado pela relação entre juros e preços dos ativos financeiros detidos pelos agentes é ineficaz, pois quando há alterações de juros, os títulos pós-fixados não sofrem variações de preço e o estoque de riqueza dos agentes fica inalterado, de modo que a demanda agregada não se modifica tão intensamente quanto seria o caso se não houvesse títulos pós-fixados. Mesmo com a recente melhoria da composição da dívida pública, em que já predominam títulos prefixados e indexados aos níveis de preços, Pires \& Andrade (2009) mostram que ainda não há eficiência do efeito riqueza para a condução da política monetária no Brasil.

Como se pode notar, somam-se vários fatores para que os juros não sejam, sozinhos, instrumentos econômicos capazes de conduzir a dinâmica inflacionária. Este problema é intensificado no Brasil, economia periférica não emissora de moeda conversível, o que leva a taxa de câmbio a ser volátil. As oscilações do câmbio implicam modificações nos preços em geral e nos preços indexados, que, cumulativamente, se moverão por duas influências: tanto por conta do próprio câmbio quanto por conta da movimentação do IPCA. Não obstante, os títulos públicos de política monetária são indexados e, ao mesmo tempo, compõem parte não desprezível dos títulos públicos que, por sua vez, dominam o estoque de riqueza financeira dos agentes. Assim, o canal riqueza não é eficiente em alterar o poder de compra dos agentes, tirando dos juros poder de controle da inflação ou, em outros termos, colocando-o maiores encargos para que possa buscar alcançar este objetivo.

Assim sendo, a insistência de se utilizarem apenas os pouco eficientes juros implica em eles serem resistentes à queda, dependerem da valorização do câmbio para segurar o IPCA e onerarem a

\footnotetext{
${ }^{5}$ A lista dos preços administrados inclui: impostos; serviços de utilidade pública cujos preços são determinados por agências reguladoras, mas baseados em contratos firmados no ato das privatizações; e derivados de petróleo; entre outros (BCB, vários anos).
} 
política fiscal. Além disso, dada a taxa mínima de atratividade que qualquer investimento precisa ter para que se efetive a decisão de produzir bens e serviços, os referidos altos juros resultam em a curva de juros do mercado financeiro nacional desestimular os investimentos produtivos. Aparte questões de custos operacionais e de investimento que dificultam uma taxa interna de retorno atraente ao investimento produtivo no Brasil em relação à de outros países emergentes, a taxa de juros básica é outro condicionante da elevada volatilidade, em baixo patamar, da taxa de investimento do País, como exposto no Gráfico 5.

Gráfico 5 -Taxa de Crescimento de Formação Bruta de Capital Fixo (TXCFBKF), 1999/1 a 2013/2, (trimestral em \%/PIB)

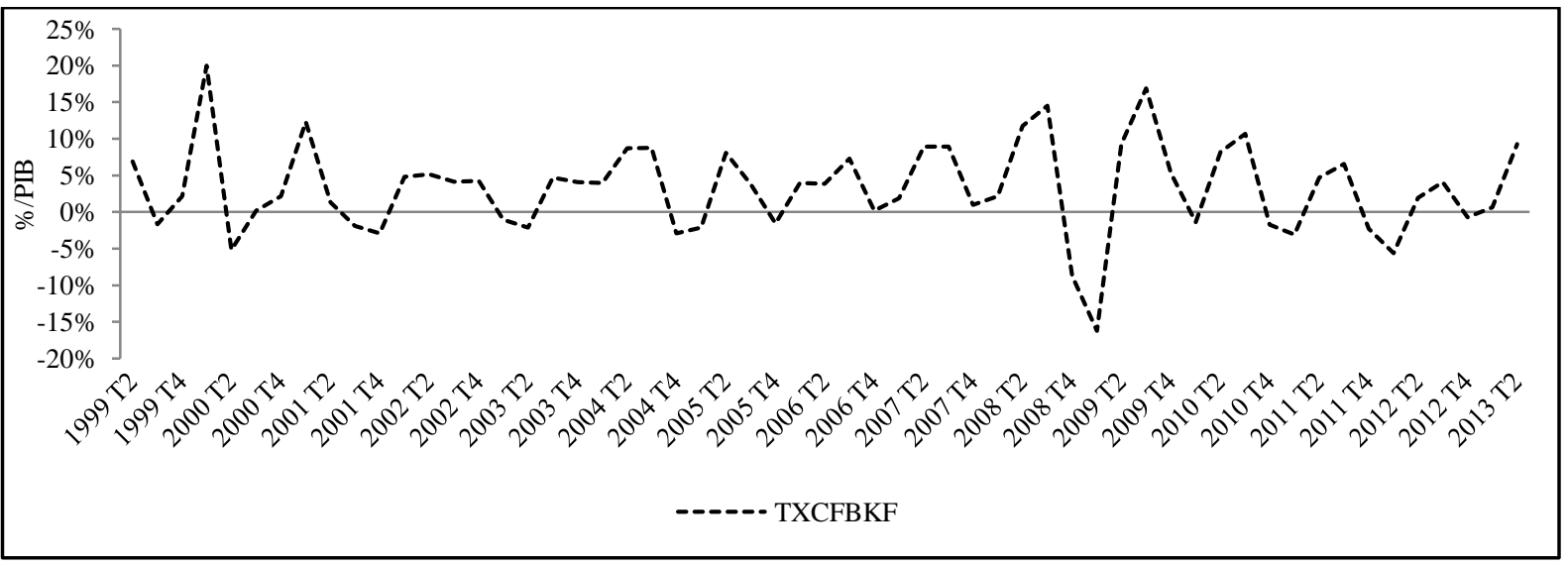

Fonte: Elaboração própria a partir de dados IPEADATA (2013)

O Gráfico 5 mostra a variabilidade do investimento no Brasil algo que, em parte, é determinado pelo comportamento dos juros, também voláteis por buscarem, praticamente sozinhos, estabilizar uma inflação multi-causada. Dada a lógica de precificação dos ativos, a primeira das quase-renda que os investidores olham é a taxa de menor risco que, no caso brasileiro, é a taxa Selic, cuja média no RMI, entre julho de 1999 e dezembro de 2013, segundo dados de BCB (2013) expostos no Gráfico 2, foi de $14,60 \%$ ao ano, imputando elevado custo de oportunidade ao investimento produtivo.

O resultado das oscilações no investimento causadas, em parte, pela atratividade dos ativos financeiros- leia-se, dívida pública, principalmente - são percebidos no Gráfico 6, abaixo, que apresenta a volatilidade na dinâmica de expansão do produto. A inconstância do investimento leva à variabilidade do produto, o que quer dizer que o comportamento do PIB no Brasil deteve tendência ascendente, porém com bastante oscilação em torno dela. Assim, a expansão da capacidade de oferta da economia foi limitada e dado que os elevados custos de oportunidade e concreto da expansão da oferta nacional, restou à economia abastecer-se de oferta externa, a que serviu a valorização da taxa de câmbio assistida no período e que, como resultados negativos, conferiu (i) 
maior concorrência ao empresário nacional, desestimulando-o ainda mais a investir e (ii) deteriorou a balança comercial dos bens de transformação e alta tecnologia e a conta corrente do balanço de pagamentos.

Gráfico 6 - Taxa de Crescimento do Produto (TXCPIB), 1999/2 a 2013/2 (trimestral em $\% /$ trimestre anterior)

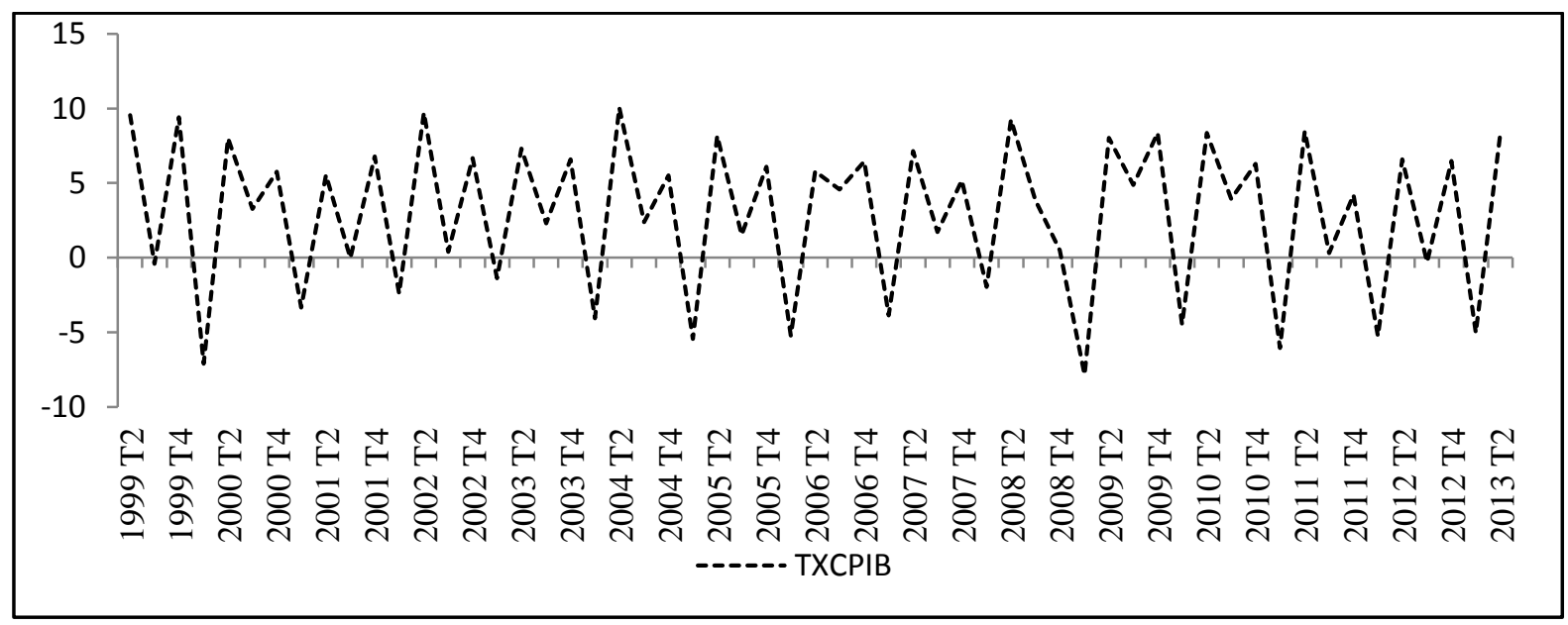

Fonte: Elaboração própria a partir de dados IPEADATA (2013)

Em suma, a manutenção da inflação dentro das bandas estabelecidas pelo RMI foi feita sob elevados custos para a economia brasileira, quais sejam, desde a dependência da valorização cambial para o controle dos preços até a influência para uma dinâmica stop and go do produto. Passa-se, agora, à uma análise empírica do comportamento dos preços no Brasil, a fim de se entender qual seus determinantes principais e de se confirmar as críticas de inspiração póskeynesiana ao RMI.

\section{Metodologia, Base de Dados e Análise dos Resultados}

\subsection{Metodologia}

A metodologia empírica envolverá a estimação do modelo econométrico de Vetores Autorregressivos (VAR), dinâmico e com o mínimo de restrições, no qual toda as variáveis são tratadas como endógenas e em que o modelo examinará as relações lineares entre as variáveis e os próprios valores defasados delas. Segundo Bueno (2008), de modo geral, pode-se especificar um modelo VAR de ordem $p$ por um vetor com $n$ variáveis endógenas, $X_{t}$, que estão conectadas entre si por meio de uma matriz $A$, conforme segue:

$A X_{t}=B_{0}+\sum_{i=1}^{p} B_{1} X_{t-1}+B_{\varepsilon_{t}}$ 
em que A é uma matriz $n x n$ que define as restrições contemporâneas entre as variáveis que constituem o vetor $n \times 1, X_{t} ; B_{0}$ é um vetor de constantes $n \times 1 ; B_{t}$ são matrizes $n \times n ; B$ é uma matriz

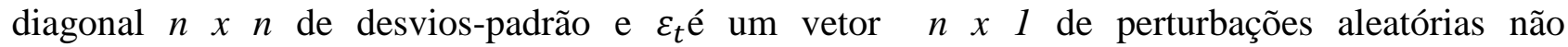
correlacionadas entre $\mathrm{si}^{6}$.

Duas considerações são necessárias acerca dos modelos VAR. Por um lado, ao se trabalhar com séries temporais, deve-se realizar testes de raiz unitária para examinar a estacionariedade da série, algo de extrema importância, pois esta condição permite que se façam inferências estatísticas sobre os parâmetros estimados, com base na realização de um processo estocástico. O diagnóstico errado da estacionariedade pode causar o problema de regressão espúria, com um alto valor do coeficiente de determinação, testes estatísticos significantes, porém sem relação significativa entre as variáveis (BUENO, 2008). Por outro lado, como o modelo VAR apresenta diversos parâmetros, ele é de difícil interpretação devido à complexa interação entre as variáveis. Logo, as propriedades dinâmicas do VAR são mais bem analisadas por meio (1) das funções de impulso-resposta e pela (2) análise de decomposição de variância (JUNIOR et al, 2011). Antes de se passarem às análises, contudo, a base de dados utilizada é apresentada.

\subsection{Base de Dados}

A fim de se realizarem as estimativas é necessário selecionarem-se variáveis macroeconômicas que influenciam na determinação da inflação, medida pelo IPCA. Sendo esta a variável que se analisará, dentre todas as regressões que serão estimadas, os resultados analisados serão os da equação em que o IPCA é a variável relevante. Neste caso, serão variáveis explicativas aquelas que se relacionam com todos os condicionantes da inflação apontados tanto do lado da demanda, representado pelo hiato do produto, quanto fatores em se fundamentam as críticas póskeynesianas, que no modelo se centrarão no câmbio nominal, que funciona como causa da inflação de oferta por pass through sobre os custos de produção,e nos preços administrados, que é uma proxy da indexação de contratos. Por fim, é necessário inserir o instrumento de política monetária, a taxa de juros, a bem de se alcançarem resultados sobre qual a influência dela sobre a inflação. Para o modelo, extraíram-se dados trimestrais das variáveis abaixo arroladas para o período de 1999/T1 - 2013/T2. As fontes do dados foram o IPEADATA (2013), o Instituto Brasileiro de Geografia e Estatística (IBGE, 2013) e o BCB (2013).

Sendo assim, o vetor de variáveis que será utilizado nos testes econométricos é composto por:

\footnotetext{
${ }^{6}$ Os choques $\varepsilon_{t}$ são chamados choques estruturais pois afetam, individualmente, cada uma das variáveis endógenas. Eles são considerados independentes entre si, visto que suas interrelações são captadas indiretamente pela mátriz $A$. Logo, a independência dos choques ocorre sem perda de generalidade (BUENO, 2008).
} 
- Taxa Selic (sob a sigla, SELIC);

- Variação dos preços administrados (PADM);

- Taxa de câmbio nominal (TXC);

- $\quad$ Hiato do Produto (GAPP) ${ }^{7}$;

- IPCA (IPCA).

enquanto que a regressão em que o IPCA encontra-se como variável dependente do modelo é dada pela seguinte equação:

$$
\begin{aligned}
\text { IPCA }_{\mathrm{t}}=\mathrm{SELIC}_{\mathrm{t}-1}+\mathrm{SELIC}_{\mathrm{t}-2}+\mathrm{SELIC}_{\mathrm{t}-3}+\mathrm{IPCA}_{\mathrm{t}-1}+\mathrm{IPCA}_{\mathrm{t}-2}+\mathrm{IPCA}_{\mathrm{t}-3}+\mathrm{GAPP}_{\mathrm{t}-1} \\
+\mathrm{GAPP}_{\mathrm{t}-2}+\mathrm{GAPP}_{\mathrm{t}-3} \\
+\mathrm{TXC}_{\mathrm{t}-1}+\mathrm{TXC}_{\mathrm{t}-2}+\mathrm{TXC}_{\mathrm{t}-3}+\mathrm{PADM}_{\mathrm{t}-1}+\mathrm{PADM}_{\mathrm{t}-2}+\mathrm{PADM}_{\mathrm{t}-3}+\varepsilon_{t}
\end{aligned}
$$

\subsection{Análise dos Resultados}

Para a aplicação empírica, foram realizados os testes de raiz unitária nas variáveis, no intuito de identificar a estacionariedade delas.A identificação das propriedades de integração das séries foram obtidas aplicando-se os seguintes testes: Dickey-Fuller Aumentado (ADF), Phillips-Perron (PP), e Kwiatkowski, Phillips, Shimidt e Shin (KPSS). Para os testes ADF e PP, a hipótese nula é de que a série possui raiz unitária (série não estacionária), enquanto que para o teste KPSS, a hipótese nula é de que a série não possui raiz unitária (série estacionária). Os resultados são reportados nas Tabelas 1 a 3, abaixo.

Tabela 1 - Teste de Estacionariedade de Dickey-Fuller Aumentado

\begin{tabular}{lccccc}
\hline \multicolumn{1}{c}{ Discriminação } & Defasagem & Constante & Tendência & Estatísticat & $\begin{array}{c}\text { Valor } \\
\text { Crítico } 1 \%\end{array}$ \\
\hline IPCA & 2 & sim & não & -3.230772 & -3.555023 \\
SELIC & 2 & não & não & -1.409746 & -2.607686 \\
PADM & 0 & sim & sim & $-6.327719^{*}$ & -4.127338 \\
TXC & 2 & não & não & -0.146292 & -2.607686 \\
GAPP & 4 & não & não & $-4.964516^{*}$ & -2.609324 \\
\hline
\end{tabular}

Fonte: Elaboração própria a partir da saída do Eviews 4.1.

Notas: Para seleção da defasagem, foi utilizado o critério de informação de Schwartz (SC). *Significativo a 1\%.

Tabela 2 - Teste de Estacionariedade de Phillips-Perron

\begin{tabular}{lcccc}
\hline \multicolumn{1}{c}{ Discriminação } & Constante & Tendência & Estatísticat & $\begin{array}{c}\text { Valor } \\
\text { Crítico } 1 \%\end{array}$ \\
\hline IPCA & $\operatorname{sim}$ & não & $-4.794928^{*}$ & -3.550396 \\
SELIC & $\operatorname{sim}$ & $\operatorname{sim}$ & $-5.163148^{*}$ & -4.127338 \\
PADM & $\operatorname{sim}$ & $\operatorname{sim}$ & $-6.224190^{*}$ & -4.127338 \\
TXC & não & não & -0.188213 & -2.606163 \\
GAPP & não & não & $-8.365339^{*}$ & -2.606163 \\
\hline
\end{tabular}

Fonte: Elaboração própria a partir da saída do Eviews 4.1.

Nota: *Significativo a $1 \%$.

${ }^{7}$ O gap do produto foi calculado pela diferença entre o PIB tendencial do periodo 1999 a 2013 e o PIB efetivo trimestral. Desta forma, choques positivos no gapsignificam insuficiência de demanda efetiva, ou seja, afastamento do PIB observado do tendencial. 
Tabela 3 - Teste de Estacionariedade de Kwiatkowski, Phillips, Shimidt e Shin

\begin{tabular}{ccccc}
\hline Discriminação & Constante & Tendência & Estatísticat & $\begin{array}{c}\text { Valor } \\
\text { Crítico } 1 \%\end{array}$ \\
\hline IPCA & $\operatorname{sim}$ & não & $0.402905^{*}$ & 0.739000 \\
SELIC & $\operatorname{sim}$ & $\operatorname{sim}$ & $0.054529^{*}$ & 0.216000 \\
PADM & $\operatorname{sim}$ & $\operatorname{sim}$ & $0.107389^{*}$ & 0.216000 \\
TXC & $\operatorname{sim}$ & sim & $0.151630^{*}$ & 0.216000 \\
GAPP & $\operatorname{sim}$ & não & $0.074918^{*}$ & 0.739000 \\
\hline
\end{tabular}

Fonte: Elaboração própria a partir da saída do Eviews 4.1.

Nota: *Significativo a $1 \%$.

Note-se que apenas a série TXC não foi estacionária, sendo necessário adotar a rotina de colocá-la em primeira diferença para que ela passe a ficar estacionária. Dando sequência à estruturação do modelo, após a realização do teste de estacionariedade, para garantir um modelo bem especificado é necessário escolher-se o número de defasagens para estimação. De modo geral, para a determinação da ordem de defasagem utiliza-se os critérios de informação dos modelos univariados, tais como: Critério de Informação de Akaike (AIC), critério de informação Schwartz (SC), Critério de Informação de Hannan-Quinn (HQ), e Erro de Predição Final (FPE). Assim, a defasagem (lags) são escolhidas através dos critérios de informação supracitadas, que visam minimizar os problemas relacionados à presença de autocorrelação nos erros do VAR. A defasagem é escolhida quando indicada por todos os testes ou por sua maioria. Como houve um empate, optouse por estimar um VAR com 3 defasagens, pois com um número maior de períodos, amplia-se o número de informações disponíveis à regressão, dando-a mais robustez.

Tabela 4 - Critério de seleção da ordem de defasagem do modelo

\begin{tabular}{lllll}
\hline Lag & FPE & AIC & SC & HQ \\
\hline 0 & 368.4793 & 20.09875 & 20.28291 & 20.16977 \\
1 & 15.45898 & 16.92297 & $18.02796^{*}$ & $17.34912^{*}$ \\
2 & 15.59867 & 16.90767 & 18.93349 & 17.68895 \\
3 & $14.07529^{*}$ & $16.74222^{*}$ & 19.68887 & 17.87863 \\
\hline
\end{tabular}

Fonte: Elaboração própria a partir da saída do Eviews 4.1.

Nota: *indica a ordem de defasagem selecionada pelo critério.

Além disso, é importante verificar a estabilidade do modelo VAR, que será estimada com as variáveis IPCA, GAPP, PADM, SELIC e DTXC. O teste de estabilidade permite analisar se todas as raízes são, em módulo, menores que um, ou seja, se estão dentro do círculo unitário o que indica que os impulsos das variáveis e as respostas sobre as demais diminuem com o passar do tempo. Neste contexto, a Figura 1 apresenta o resultado que corrobora com a condição de estabilidade. 
Figura 1 - Teste de Estabilidade do VAR

Inverse Roots of AR Characteristic Polynomial

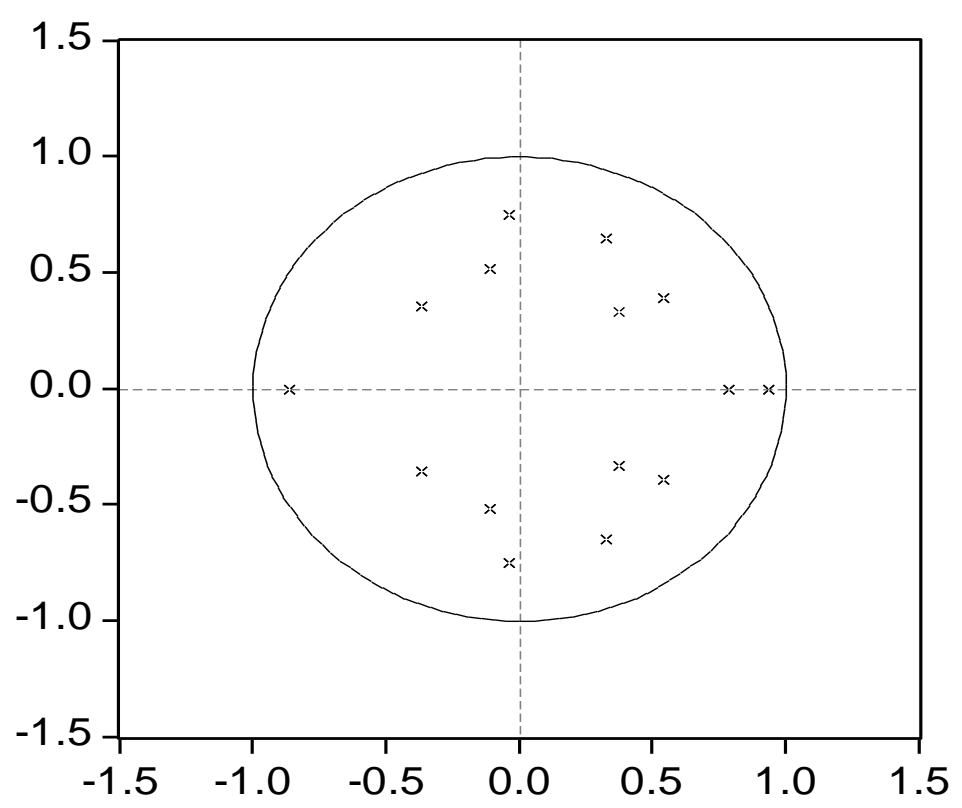

Fonte: Elaboração Própria a partir da saída do Eviews 4.1.

Para definir o ordenamento estatisticamente consistente das variáveis, foi utilizado o Granger Block Exogeneity Wald Test. As estatísticas mostram a significância conjunta de cada variável endógena defasada para cada equação do VAR. Os resultados estão apresentados na Tabela 5.A partir da estatística Qui-Quadrado de Wald correspondente à estatística de significância conjunta de todas variáveis endógenas defasadas, organizam-se as variáveis das mais exógenas (menores valores da estatística) para as mais endógenas. Sendo assim, baseando-se na Tabela 5, a ordenação correta é a seguinte: IPCA, PADM, SELIC, GAPP e DTXC.

Tabela 5 -Teste de Wald para exogeneidade em bloco de Granger

\begin{tabular}{lllll}
\hline & Variável Dependente & $X^{\mathbf{2}}$ & df & Prob (total) \\
\hline 1 & IPCA & 27.86933 & 12 & 0.0058 \\
2 & PADM & 26.80755 & 12 & 0.0082 \\
3 & SELIC & 26.15365 & 12 & 0.0102 \\
4 & GAPP & 14.92389 & 12 & 0.2456 \\
5 & DTXC & 5.171609 & 12 & 0.9520 \\
\hline
\end{tabular}

Fonte: Elaboração própria a partir da saída do Eviews 4.1.

Como já observado, em função da dificuldade de se interpretarem os coeficientes estimados para o modelo VAR, é comum usar para as análises a função de impulso-resposta e a decomposição da variância. Segundo Vartanian (2010), a função de resposta ao impulso é uma técnica que possibilita avaliar os efeitos de um choque em uma série temporal sobre outra série. Em outras palavras, os resultados apresentados na função de resposta ao impulso permitem avaliar 
adequadamente os resultados de choques em qualquer uma das variáveis. Enders (2010) sumariza dizendo que esta função representa o horizonte temporal dos efeitos dos choques das demais variáveis no VAR sob uma determinada variável. Isso posto, as funções impulso-resposta das variáveis selecionadas sob o IPCA, objeto de análise neste trabalho, estão apresentadas na Figura 2.

Figura 2 - Função Resposta da Inflação a um Impulso nas Variáveis Selecionadas

Response to Cholesky One S.D. Innovations \pm 2 S.E.
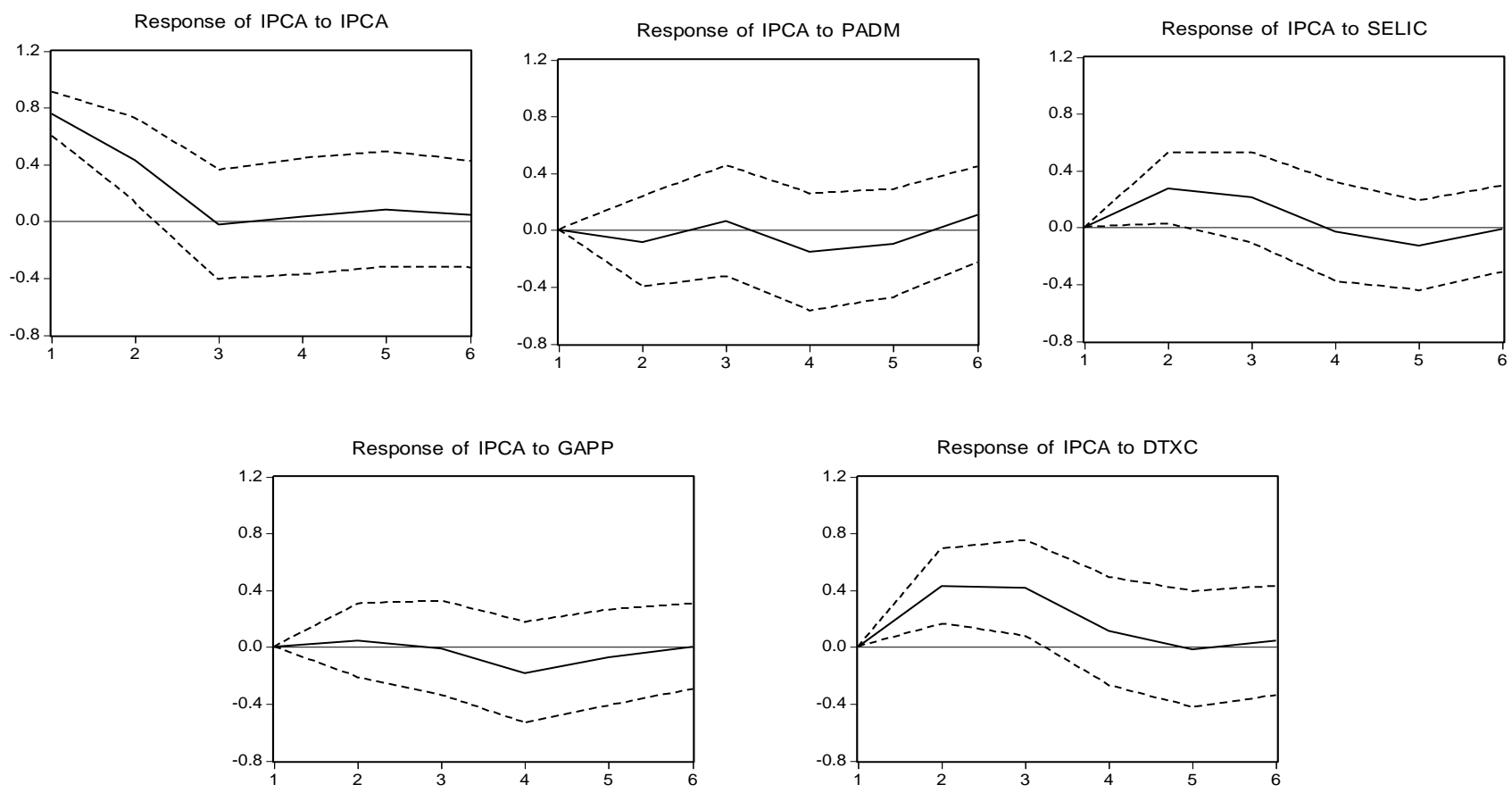

Fonte: Elaboração própria a partir da saída do Eviews 4.1.

A partir da Figura 2, é possível perceber que a principal resposta da inflação ocorre com relação à ela mesmo e à taxa de câmbio. Assim, é possível inferir que a inflação brasileira apresenta uma tendência expectacional em que a percepção de alterações futuras dos preço conduz à modificações presentes deles, ou seja, os agentes que detêm capacidade de marcação de preço se antecipam às expectativas de inflação futura. Este cenário leva à um cenário de difículdade para a condução da política monetária, pois há a presença de profecias autorrealizáveis sobre o comportamento dos preços: espera-se um aumento deles que, quando convencionado pela opinião média, acaba por se tornar efetivo. Em termos de policy making a inflação por expectativas exige, segundo Keynes (1964), que a AM seja capaz de conduzir as convenções dos agentes para crenças de que ela está sob controle, de forma que a política monetária "pode ser facilmente bem sucedida se a opinião pública a considerar razoável e compatível com o interesse público, assentada numa sólida convicção e promovida por uma autoridade que não é suscetível de ser substituída"(KEYNES, 1964, p. 203).Ressalte-se que, de forma bastante diversa do que o RMI 
postulado, a crença ou a descrença na AM não decorre de ela enganar os agentes com promessas não cumpridas de conter o viés inflacionário, mas resultará das convenções que se formarem no sistema econômico sobre qual a reação da referida Autoridade aos vários choques que podem ocorrer nos condicionantes da inflação. À título de ilustração da anteposição entre ambas as perspectivas, na teoria pós-keynesiana, o Estado pode estar em superávit nominal e, ainda assim, a inflação por expectativas ocorrer, por conta de os agentes convencionarem que a reação da AM à uma quebra de safra ou à um intenso conflito distributivo é aquém da necessária para a estabilização do nível de preços.

Com relação à taxa de câmbio, o efeito de variações cambiais sobre os preços é significativa, rápida e persistente, confirmando os resultado alcançados por Arestis et al (2009) e Modenesi \& Araújo (2012). Portanto, os preços são sensíveis ao câmbio, de forma que se justificam as intervenções do BCB no mercado cambial visando arrefecer as tendências de variação cambial substancial. Em termos de condução de política, as citadas intervenções devem continuar, se possível com o mesmo formato recentemente, via swap cambial reverso, que viabilizam influenciar o câmbio sem ser preciso alterar-se a taxa de juros. Desta forma, (i) tira-se um encargo dos juros básicos, reduzindo sua volatilidade e, em consequência, dando-o maior previsibilidade e (ii) confere-se maior autonomia à taxa de juros da política monetária para que se direcione diretamente aos problemas domésticos.Ademais, controles macroprudenciais sobre o mercado de câmbio são requeridos, para que os fluxos internacionais de capital exerçam menor pressão sobre a taxa de câmbio e para que se reforce os dois efeitos acima arrolados.

A resposta do IPCA à Selic traz um resultado interessante: em um primeiro momento, impacta-se positivamente o nível de preços e em um segundo, negativamente. Este resultado parece inferir que os agentes antecipam-se ao declínio da atividade econômica que, com defasagem, o aumento dos juros causará, buscando ganhar mais no imediato curto prazo após a remarcação dos juros, para compensar o menor ganho decorrente do esfriamento dos componentes da demanda no médio prazo. Se esta inferência é correta, reforça-se o papel das causal das expectativas sobre a dinâmica inflacionária no Brasil. Assim, sendo, para a política monetária, esta reação do IPCA ao choque dos juros nominais significa que, com algum delay, os preços reagem favoravelmente à taxa de juros de forma que, quanto mais a AM conseguir se antecipar aos condicionantes da variações do IPCA, como o câmbio e as expectativas, e mais coordenada forem as políticas monetária e cambial, menos instáveis os preços serão e melhor estado de confiança terá o empresário em suas expectativas de receitas futuras - que dependem dos preços de oferta de seus produtos melhorando o cálculo da eficiência marginal do seu bem de capital e incitando-o ao investimento. 
Os resultados mostram que choques nos preços administrados, por sua vez, exerceram pouca influência sobre o IPCA e, em geral, foram no sentido de reduzir a velocidade de variação dos preços. Este resultado se deu pois ao longo do período 1999/2013, os preços administrados subiram em ritmo menor do que o IPCA, como mostrou o Gráfico 3. Saliente-se que isso quer dizer que os preços administrados aceleraram, mas menos que a inflação total. Como há uma endogenia entre IPCA e preços administrados, pode-se argumentar que, embora estes gerem inflação, eles acabaram por causá-la em celeridade menor do que se verificaria caso os preços administrados fossem sistematicamente superiores à variação da inflação em geral. Neste contexto, confirma-se o argumento de Arestis et al (2009) dos impactos da valorização cambial ocorrido após 2003 sobre os preços administrados, suavizando-se seus reajustes. Ademais, este resultado chama a atenção para os possíveis efeitos do represamento dos preços administrados sobre a inflação total, algo notável quando se trata dos combustíveis. As implicações de política monetária vão no sentido de reafirmar a importância da necessidade de controle sobre o mercado cambial além de, caso utilizado, o represamento de preços administrados ocorra com capacidade de diluição intertemporal da defasagem dos preços controlado sobre os demais, pois, caso ocorram reajustes intensos em algum momento do tempo, podem-se ter picos inflacionários, com repercussões funestas sobre as expectativas inflacionárias dos agentes.

Por fim, os choques no gap do produto, isto é, distanciamentos do produto observado do tendencial, possuíram poucos efeitos causais sobre a inflação nos resultados obtidos pela funções de impulso-resposta. Tal resultado está em consonância com a crítica constantemente feita pelos póskeynesianos à condução da política monetária sob o RMI. Tal resultado, relacionado à resposta do IPCA aos choques da Selic, mostra que, muito embora a demanda agregada não seja uma causa expressiva do comportamento do IPCA, o uso da taxa de juros para arrefecer a demanda leva ao controle da inflação. Para ilustrar esta relação entre as causas da inflação no Brasil e forma de controlá-la, são válidas as palavras de Keynes "a elevação da taxa de juros [...] pertence às espécies de remédio que curam a doença matando o paciente" (1964, p. 323).

Após a análise das funções impulso-resposta, a segunda forma de se analisarem os modelos VAR é a Análise da Decomposição da Variância (ADV). Nos modelos ADV, a porcentagem da variância do erro de previsão é decorrente de cada variável endógena, ao longo do horizonte de previsão (BUENO, 2008). Em outras palavras, esta análise consiste na identificação da responsabilidade de cada uma das variâncias na explicação da variância de todas as variáveis do sistema, após um choque, servindo como classificação da importância relativa de cada variável na determinação dela mesma e das demais (VARTANIAN, 2010). Os resultados da ADV estão expostos na Tabela 6 , a seguir. 
Tabela 6 - Decomposição da Variância da inflação (em \%)

\begin{tabular}{ccccccc}
\hline Período & S.E. & IPCA & PADM & SELIC & GAPP & DTXC \\
\hline 1 & 0.757325 & 100.0000 & 0.000000 & 0.000000 & 0.000000 & 0.000000 \\
& & $(0.00000)$ & $(0.00000)$ & $(0.00000)$ & $(0.00000)$ & $(0.00000)$ \\
2 & 1.012075 & 73.89368 & 0.658652 & 7.407484 & 0.196549 & 17.84363 \\
& & $(9.66306)$ & $(3.24991)$ & $(5.35697)$ & $(2.04605)$ & $(8.05772)$ \\
3 & 1.115792 & 60.82910 & 0.851213 & 9.637265 & 0.168283 & 28.51414 \\
& & $(11.7341)$ & $(4.64432)$ & $(7.02064)$ & $(2.94409)$ & $(10.8153)$ \\
4 & 1.147340 & 57.60915 & 2.647714 & 9.190963 & 2.654412 & 27.89776 \\
& & $(11.5456)$ & $(5.70030)$ & $(6.51445)$ & $(4.93672)$ & $(10.5265)$ \\
5 & 1.164097 & 56.49565 & 3.252696 & 10.14496 & 2.988288 & 27.11841 \\
& & $(11.5358)$ & $(6.26992)$ & $(6.42481)$ & $(5.32021)$ & $(10.0771)$ \\
6 & \multirow{2}{*}{1.171099} & $\mathbf{5 5 . 9 8 9 5 0}$ & $\mathbf{4 . 0 7 9 0 4 3}$ & $\mathbf{1 0 . 0 3 1 4 8}$ & $\mathbf{2 . 9 5 3 8 5 7}$ & $\mathbf{2 6 . 9 4 6 1 2}$ \\
& & $(11.4915)$ & $(6.39787)$ & $(6.40083)$ & $(5.21157)$ & $(9.96635)$ \\
\hline
\end{tabular}

Fonte: Elaboração própria a partir da saída do Eviews 4.1.

Os resultados dos testes ADV são semelhantes às análises impulso-resposta, de forma que as explicações feitas acima reproduzem-se. Desta forma, a ADV mostra que própria inflação é o principal fator responsável de seu comportamento (55\% após seis trimestres), de forma que as expectativas inflacionárias resultam em profecias autorrealizáveis que implicam um caráter inercial à dinâmica de preços no Brasil. Ademais, a ADV mostra que o câmbio é o segundo fator mais explicativo do comportamento do IPCA brasileiro, 27\%. Ambos os fatores são destacados como causais à inflação nas críticas pós-keynesianas à condução da política monetária sob a égide do RMI. A taxa de juros, por sua vez, instrumento de reação do BCB, participa de $10 \%$ da dinâmica do IPCA, após 6 trimestres. Isso demonstra a reconhecida defasagem do instrumento que, após alterar as condições de liquidez da economia e os custos de oportunidade dos diferentes ativos, impacta sobre a demanda agregada, influenciando-a e, assim, afetando a dinâmica dos preços (além, é claro, do impacto indireto de maiores juros sobre o câmbio e, destes, para os preços). As variações dos preços administrados (4\%) e do comportamento do gap do produto (2,95\%) são pouco significativos na explicação da performance dos preços no Brasil.

Em suma, as análises realizadas confirmam as críticas pós-keynesianas feitas aos resultados do RMI no Brasil: as causas da inflação são multideterminadas, com forte impacto inercial causado pelo comportamento convencional dos agentes, o que (i) gera uma tendência de antecipação das variações positivas dos preços e uma consequente perpetuação da inflação; (ii) o câmbio é um fator muito relevante na explicação da dinâmica inflacionária do País; (iii) a taxa de juros é um instrumento com pouco impacto imediato sobre a inflação; (iv) os preços administrados condicionam a dinâmica inflacionárias, porém, seguindo-se Arestis et al (2009), devido à apreciação cambial a velocidade de avanço deles foi inferior ao ritmo do IPCA, de forma que eles explicaram pouco do aumento dos preços e, por fim, (v) o lado da demanda não foi um fator relevante na explicação do comportamento do IPCA. 


\section{Considerações Finais}

A dinâmica inflacionária no Brasil, como mostraram os resultados dos testes econométricos, decorre, em muito, das próprias expectativas acerca de sua dinâmica futura e, ademais, dos impactos do câmbio (proxy para inflações de custo). Em nenhum dos casos, portanto, a inflação decorre de excessos de demanda causados por viés inflacionário. Pode-se ter o paroxismo de mesmo diante de um superávit nominal do setor público, a inflação não ceder, por conta de antecipação presente de variações futuras de preços. Embora seja este um fenômeno aparente, suas causas essenciais não são por excesso de demanda, mas pode decorrer de conflito distributivo entre lucros e salários ou entre produtores de matérias-primas e produtores de bens finais ou por exercício de poder de mercado ou mesmo por remarcações de preços de firmas multinacionais que se antecipam à eventuais perspectivas de desvalorizações cambiais, ampliando seus markups atuais para que seus lucros em dólares não se reduzam. O que a política de juros, função de reação do RMI, pode fazer nestes casos é ampliar os custos de oportunidade do investimento produtivo, reduzindo-o desde que a eficiência marginal do capital arrefeça-se pari passu em função de piores expectativas de demanda futura. Logo, perceba-se, para que os juros impliquem qualquer mudança na dinâmica inflacionária é necessário penalizar-se o avanço da riqueza, como se a solução da inflação fosse ser alcançada por um autoflagelação social.

Sobre o câmbio, a taxa de juros possui maior impacto, desde que as expectativas dos investidores internacionais sancionem o diferencial de juros doméstico em relação à média internacional. Contudo, deixar a taxa de juros sem qualquer auxílio no controle da demanda e do câmbio é encarregá-la por demais. Daí a necessidade de coordenação de políticas econômicas com vistas ao incentivo dos investimentos produtivos compatíveis com níveis de demanda efetiva de equilíbrio, a lá Keynes (1964, cap. 3). As recentes intervenções, diga-se de passagem, incisivas, do BCB no mercado de cambial por meio de swaps cambiais reversos, ancoradas no amplo estoque estratégico de reservas internacionais permitiram à taxa de juros menor sensibilidade, dando-a maior liberdade para estimular os investimentos produtivos, por sua vez, também estimulados pela oferta de hedge cambial que os referidos swaps oferecem para a compra de bens de capital do exterior, para a tomada de finance externo e para orçamento de custos de produção cujos preços sejam atrelados ao dólar. Neste sentido, as medidas de controle de capitais colocadas sobre o capital externo de portfólio e de outros investimentos de curto prazo contribuíram ainda mais para o controle do câmbio sem o uso dos juros.

Portanto, isso mostra que a política monetária precisa de coordenação com outras políticas para que ela consiga alcançar seus objetivos, dentre os quais, o mais importante é o alcance do pleno emprego sem descontrole inflacionário. Neste sentido, como mostra Keynes (1964) a taxa de 
juros continua sendo o instrumento essencial da política monetária, contudo, ele não se dedica à repressão da demanda, mas ao estímulo dela, enquanto que as políticas cambial, de rendas e fiscal, cada uma com seu instrumentos cuidam, respectivamente, da administração do câmbio, do conflito entre a distribuição funcional da renda e da demanda agregada, respectivamente. Por fim, nesta lógica operacional das políticas econômicas, não percebe-se autoflagelação social, mas busca racional e disciplinada do pleno emprego e do fim da distribuição desigual da renda, os dois piores males que afligem o capitalismo moderno, conforme aponta Keynes (1964).

\section{Referências}

ARESTIS, P.New monetary policy and Keynes. European Journal of Economics and Economic Policy: Intervention, v. 3, n. 3, p. 245-262, 2006.

New Macroeconomic Consensus: a critical appraisal. The Levy Economics Institute of Bard College Working Paper, n. 564, 2009.

ARESTIS, P. \& SAWYER, M..Keynesian economic policies for the new milleniun. The Economic Journal, v. 108, n. 446, p. 181-195, 1998. crossref http://dx.doi.org/10.1111/1468-0297.00281

. Can monetary policy affect the real economy? The Levy Economics Institute of Bard College Working Paper, n. 355, 2002.

.On the effectiveness of monetary policy and fiscal policy. The Levy Economics Institute of Bard College Working Paper, n. 369, 2003a.

.The nature and role of monetary policy when money is endogenous. The Levy Economics Institute of Bard College Working Paper, n. 374, 2033b.

Moving from Inflation Targeting to prices and incomes policy. Panoeconomicus, v. 1, n. 1, pp. 1-17, 2013.

ARESTIS, P.; FERRARI FILHO, F.; PAULA, L..A nova política monetária: uma análise do regime de metas de inflação no Brasil. Economia e Sociedade, vol. 18, p. 1-30, 2009.

crossrefhttp://dx.doi.org/10.1590/S0104-06182009000100001

BANCO CENTRAL DO BRASIL. Séries temporais do Banco Central do Brasil.Disponível em: <http://www.bcb.gov.br>. Acesso em outubro 2013.

. Relatório de Inflação. Vários anos. Disponível em: 〈http://www.bcb.gov.br/htms/relinf>. Acesso em outubro 2013.

BARRO, R. J.; GORDON, D. B..Rules, discretion and reputation in a model of monetary policy" Journal of Monetary Economics, vol. 12, p.101-121, 1983. cross ref $h$ ttp://dx.doi.org/10.1016/0304$\underline{3932(83) 90051-X}$

BERNANKE, B \& MISHKIN, F. Inflation targeting: a new framework for monetary policy? NBER Working Paper Series, n. 5893, 1997.

BUENO, R. L.. Econometria de séries temporais. São Paulo: Cengage, 2008. 
CARVALHO, F. J. C. de. Uma contribuição ao debate em torno da eficácia da política monetária e algumas implicações para o Brasil. Revista de Economia Política, v. 25, n. 4, p. 323-336, 2005. crossrefhttp://dx.doi.org/10.1590/S0101-31572005000400001

CARVALHO, F. J. C. de.\& FERRARI FILHO, F.. El presidente Lula da Silva em el primer tercio de su mandato. Investigación Econômica, v. 63, n. 249, p. 55-74, 2004.

ENDERS, W. Applied Econometric Time Series. Nova York: John Wiley \&. Sons, 2010.

GOODFRIEND, M. \& KING, R. G..The new neoclassical synthesis and the role of monetary police. National Bureau of Economic Research Macroeconomics Annual 1997, vol. 12, p.231-296, 1997.

INSTITUTO BRASILEIRO DE GEOGRAFIA E ESTATÍSTICA. Disponível em: <www.ibge.gov.br>. Acesso em dezembro 2013.

IPEADATA. Macroeconomia.Disponível em: 〈www.ipeadata.gov.br〉. Acesso em outubro 2013.

JUNIOR, J. C. A. da S; MENEZES, G..; FERNANDEZ, R. N. Uma análise VAR das relações entre o mercado de ações e as variáveis macroeconômicas para o Brasil. Revista Economia e Desenvolvimento, n.23, 2011.

KEYNES, J. M.. The General Theory of Employment, Interestand Money. Nova York: HBC, 1964.

KYDLAND, F. E. \& PRESCOTT, E. C. Rules than discretion: thein consistency of optimal plans. The Journal of Political Economy, vol. 85, n. 3, p. 473-492, 1977. crossrefhttp://dx.doi.org/10.1086/260580

MANKIW, N.G. Macroeconomia. Rio de Janeiro: Editora LTC, 2010.

MODENESI, A. M. Regimes Monetários: teoria e a experiência do real. Barueri: Manole, 2005.

MODENESI, A. M.\& ARAÚJO, E. C. de. Determinantes macroeconômicos da inflação: implicações para a política monetária. In: FERRARI FILHO, F.; PAULA, L. F. R. de. A crise financeira internacional: origens, desdobramentos e perspectivas (orgs.). São Paulo: Unesp, p. 187190, 2012.

OREIRO J. \& CURADO, M. Metas de inflação: uma avaliação do caso brasileiro. Ensaios FEE, v. 33, n.2, p. 127-146, 2005.

OREIRO, J. L \& PAULA, L.F. Uma agenda de reformas macroeconômicas para o crescimento sustentado com estabilidade de preços e equidade social.Economia e Tecnologia, vol. 06, n. 20, 2010.

OREIRO, J. L.\& PADILHA, R. A. Inflação e Crescimento no Longo Prazo. Economia e Tecnologia, vol. 02, n.07, 2006.

PIRES, M. C. C. \& ANDRADE, J. P.. Uma Análise da Transmissão da Política Monetária e o Canal da Dívida Pública com Aplicação aos Dados Brasileiros. Economia Aplicada, vol. 13, n. 4, p. 439-462, 2009. crossrefhttp://dx.doi.org/10.1590/S1413-80502009000400005

TAYLOR, J. B.. Discretion versus policy rules in practice. Carnegie-Rochester Conference Series on Public Policy, n. 39, p.195-214, 1993. cross ref http://dx.doi.org/10.1016/0167-2231(93)90009-L 
A core of practical macroeconomics. The American Economic Review, vol. 87, n. 2, p.233-235, 1997.

VARTANIAN, P. R. Choques Monetários e Cambiais sob Regimes de Câmbio Flutuante nos Países Membros do Mercosul: Há Indícios de Convergência Macroeconômica?EconomiA, vol.11, n.2, p.435-464, 2010. 